\title{
A novel synonymous SNP (A47A) of the TMEM95 gene is significantly associated with the reproductive traits related to testis in male piglets
}

\author{
Liangliang Liu ${ }^{1}$, Shuai $\mathrm{Yu}^{2}$, Rui Chen ${ }^{2}$, Xiaoyan $\mathrm{Lv}^{3}$, and Chuanying Pan ${ }^{2}$ \\ ${ }^{1}$ Department of Statistics and Information, School of Business Information, Shanghai University of \\ International Business and Economics, Shanghai, 201620, P.R. China \\ ${ }^{2}$ College of Animal Science and Technology, Northwest A\&F University, Shaanxi Key Laboratory of \\ Molecular Biology for Agriculture, Yangling, Shaanxi, 712100, P.R. China \\ ${ }^{3}$ National Swine Foundation Seed Farm of Ankang Yangchen Modern Agriculture Group Co. Ltd, Ankang, \\ Shaanxi, 725000, P.R. China
}

Correspondence to: Liangliang Liu (lingyun79626@126.com) and Chuanying Pan (chuanyingpan@126.com)

Received: 23 January 2017 - Revised: 8 June 2017 - Accepted: 13 June 2017 - Published: 25 July 2017

\begin{abstract}
Transmembrane protein 95 (TMEM95) is located on the acrosomal membrane of the sperm head involved in the acrosome reaction; thus, it is regarded as affecting spermatogenesis and reproduction traits. The aim of this study was to explore the novel single nucleotide polymorphisms (SNPs) within the pig TMEM95 gene as well as to evaluate their associations with the testicular sizes in male Landrace (LD) and Large White (LW) breeds. After pool sequencing and bioinformatics analysis, only one novel coding SNP was found in exon 1, namely NC_010454.3: g.341T > C, resulting in a synonymous mutation (A47A). This SNP could be genotyped using the StuI polymerase chain reaction-restriction fragment length polymorphism (PCR-RFLP) assay. The minor allelic frequencies (MAFs) were 0.259 and 0.480 in the LD and LW breeds. Their polymorphism information content (PIC) values were 0.310 and 0.375 . The LW population was at the Hardy-Weinberg equilibrium (HWE) $(p>0.05)$, whereas the LD population was not $(p<0.05)$. Association analyses demonstrated that a significant relationship was found between this A47A polymorphism and testis weight at 40 days of age in the LW population ( $p=0.047$ ), and the heterozygote individuals showed lower testis weight than those with other genotypes. Moreover, this SNP was significantly associated with three testis measurement traits at 15 days of age in the LW population $(p<0.05)$; the individuals with genotypes TT and TC showed consistently superior testis measurement traits than those with genotype CC. These findings demonstrate that the A47A polymorphism had a significant effect on testis measurement traits, suggesting that the TMEM95 gene could be a candidate gene associated with reproductive traits. These results could contribute to breeding and genetics programs in the pig industry via DNA marker-assisted selection (MAS).
\end{abstract}

\section{Introduction}

During the past 20 years, there have been great, increasing improvements in the global pig industry, but reproduction still remains a severe issue. Although Large White (LW) and Landrace (LD) pigs are the most popular breeds in many countries, especially in western China, they have some reproductive trait defects (Bergfelder-Drüing et al., 2015), e.g., reproductive barriers. It is well known that reproduction traits are determined by both females and males (Beerda et al., 2008; Pausch et al., 2014); however, to date, numerous studies on reproduction traits of female pigs have been published, but the study of male reproductive traits is limited. Owing to the more important role of males in reproduction in the pig industry, male reproduction should be emphasized in the current pig industry (Mack et al., 2014).

It is generally known that the male reproduction traits are complex quantitative traits controlled by numerous minor 
genes based on polygenic hypothesis, and DNA markers can further improve genetic selection. Therefore, many breeders prefer the use of DNA markers to traditional methods for selection and breeding of pig, as well as characterization and conservation of genetic resources (Fontanesi et al., 2012; Fischer et al., 2015). Currently, identifying single nucleotide polymorphisms (SNPs) of potential candidate genes and their associations with male reproductive traits is of importance in the DNA marker-assisted selection (MAS) approach (Uimari et al., 2011; Zhang et al., 2009; Ren et al., 2017). However, to date, limited information about the candidate genes affecting male pig reproductive traits is available. Thereby, it is crucial to determine effective DNA markers from candidate genes associated with male reproductive traits in breeding and genetics of pig. At present, candidate family genes (such as the $T M E M$ family) are usually used to identify candidate genes influencing reproductive traits in order to enhance male reproductive traits in pigs using MAS.

As a member of the TMEM family, the transmembrane protein 95 (TMEM95) gene is located on chromosome 17 in Homo sapiens (human), on chromosome 17 in Pan troglodytes (chimpanzee), on chromosome 11 in Mus musculus (house mouse), on chromosome 10 in Rattus norvegicus (Norway rat), on chromosome 19 in Bos taurus (cattle), on chromosome 11 in Ovis aries (sheep) and on chromosome 12 in Sus scrofa (pig). TMEM95 is located on the acrosomal membrane of the sperm head involved in the acrosome reaction (Pausch et al., 2014). Spermatozoa of $\mathrm{mt} / \mathrm{mt}$ animals, deficiency of TMEM95, demonstrated no fluorescence at the acrosomal membrane, implying that successful fertilization by spermatozoa of $\mathrm{mt} / \mathrm{mt}$ animals might be compromised, which was consistent with the equatorial segment of the acrosome and contact of the spermatozoon with the cell membrane of the oocyte (Bedford et al., 1979; Palermo et al., 1997; Pausch et al., 2014; Ramasamy et al., 2014). Therefore, TMEM95 is hypothesized to affect spermatogenesis, and it will be possibly associated with male reproductive traits.

However, until now, there had been no information about the precise function of TMEM95 except bovine TMEM95. Bovine TMEM95 has a highly conserved single-pass type I transmembrane protein consisting of 183 amino acids (aa) with a predicted extracellular N-terminal signal peptide (Zhang et al., 2016), a 23-aa transmembrane domain and an 8-aa intracellular C-terminal domain (Pausch et al., 2014). Importantly, the premature stop codon (C161X) of bovine TMEM95 is located within the predicted transmembrane domain and truncates the protein, thus this mutation could cause idiopathic male subfertility in cattle (Pausch et al., 2014). However, its real function and novel genetic variations are unknown in many other species.

To date, no novel mutations have been reported in the pig TMEM95 gene. Moreover, whether the novel SNPs of the pig TMEM95 gene (if present) is significantly associated with male pig reproduction remains elusive. Herein, we firstly re- port the identification of a synonymous mutation (A47A) at the pig TMEM95 gene and describe a method based on a StuI PCR-RFLP for the detection. In addition, the relationship between this SNP and the testicular measurement traits are firstly evaluated, which would be of benefit in identifying candidate genes related to reproductive traits in order to increase reproduction traits related to testis in pig as well as to aid the pig industry using MAS.

\section{Experimental section}

\subsection{Animal sources and data collection (testicular traits)}

A total of 289 testis samples were obtained from male piglets belonging to two breeds: Landrace (LD) and Large White (LW) piglet herds, which are located at a national pig breeding farm, Ankang, Shaanxi, China (Chen et al., 2016; Ren et al., 2017). Among these, all LD male piglets $(n=99)$ were 40 days old, $32.63 \%$ of LW piglets $(n=62)$ were 40 days old, and $67.37 \%$ of LW piglets $(n=128)$ were 15 days old. Data about testis weight (TW), testis long circumference (TLC) and testis short girth (TSG) were obtained from the testicular tissues, which were used for association evaluation analysis (Chen et al., 2016; Ren et al., 2017).

\subsection{Genomic DNA isolation and DNA pool construction}

Genomic DNA of 289 samples was isolated from testis tissue following the procedure as described by Lan et al. (2007). The quantification of genomic DNA concentration was assayed, and the working solution of each DNA samples was $50 \mathrm{ng} \mathrm{L}^{-1}$ (Wu et al., 2014; Jia et al., 2015). A total of 50 DNA samples from each breed were randomly selected to construct genomic DNA pools. The genomic DNA pools were used as template for PCR amplification and exploring genetic variation of the TMEM95 gene.

\subsection{Primer design, PCR amplification and sequencing}

Based on Sus scrofa TMEM95 gene sequences (NC_010454.3, GI:347618782), a total of four pairs of primers ( $\mathrm{P} 1-\mathrm{P} 4$, Table 1$)$ were designed to amplify the entire exon 1-7 and their flanking regions within the TMEM95 gene, which covering all coding region of this gene.

The PCR was carried out in $50 \mu \mathrm{L}$ of reaction volume containing $2.0 \mu \mathrm{L}$ pool genomic DNA, $1.0 \mu \mathrm{L}$ of each primer (forward and reverse primer), $32 \mu \mathrm{L} 2 \times$ Eco Taq PCR super mix (+dye) and $14 \mu \mathrm{L} \mathrm{ddH_{2 }}$ O. The touch-down PCR protocol was as follows: $5 \mathrm{~min}$ at $95^{\circ} \mathrm{C}$; two cycles of $94^{\circ} \mathrm{C}$ for $30 \mathrm{~s}$, annealing from 68 to $52^{\circ} \mathrm{C}$ by $2^{\circ} \mathrm{C}$ decreases for $30 \mathrm{~s}$, and $72^{\circ} \mathrm{C}$ for $30 \mathrm{~s} ; 30$ cycles of $94^{\circ} \mathrm{C}$ for $30 \mathrm{~s}, 50^{\circ} \mathrm{C}$ annealing for $30 \mathrm{~s}$ and $72{ }^{\circ} \mathrm{C}$ for $30 \mathrm{~s}$; a final extension at $72^{\circ} \mathrm{C}$ for $10 \mathrm{~min}$; and subsequent cooling to $4^{\circ} \mathrm{C}$.

The total $50 \mu \mathrm{L}$ of PCR products was gel-purified using the EasyPure Quick Gel Extraction Kit (TransGene Biotech, 
Table 1. Amplification PCR primer sequences of the pig TMEM95 gene.

\begin{tabular}{llrll}
\hline Primer & Primer sequences $\left(5^{\prime}>3^{\prime}\right)$ & Sizes $(\mathrm{bp})$ & Covering area & Detection methods \\
\hline P1 & F:TGCTCCAGAACTTCCAACTGTCCC & 1407 & $\begin{array}{l}\text { Exon 1-6, intron 1-5 } \\
\text { and partial intron 6 }\end{array}$ & $\begin{array}{l}\text { Pool DNA sequencing; } \\
\text { PCR-RFLP }\end{array}$ \\
P2 & $\begin{array}{l}\text { R:GAGGCTCTTCTGACCCTATCCC } \\
\text { F:GATTCTGCTCCTCTCTGTCTCGGG }\end{array}$ & 1686 & $\begin{array}{l}\text { Partial exon 6, entire exon 7 } \\
\text { and partial intron 6 }\end{array}$ & $\begin{array}{l}\text { Pool DNA sequencing } \\
\text { P3 }\end{array}$ \\
& $\begin{array}{l}\text { R:ATGGAGAGGCTTGAATGTCAGGGG } \\
\text { F:CTCGTGGGGAAGAAACAT }\end{array}$ & 776 & Partial exon 7 & Pool DNA sequencing \\
P4 & $\begin{array}{l}\text { R:GGACCAAACAGCAGCATT } \\
\text { F:GCCAGGCCCACTAAATCT }\end{array}$ & 789 & Partial exon 7 & Pool DNA sequencing \\
& R:CATCACAGCCACAGCAACA & & & \\
\hline
\end{tabular}

Beijing, China). The purified fragments were inserted into the pGEM-T easy vector (Promega, USA). The colony PCR was used to verify the positive colonies and those were sequenced via a sequencing service (Genscript, Nanjing, China) (Yang et al., 2016).

\subsection{Genotyping the A47A SNP of the pig TMEM95 gene by the Stul PCR-RFLP}

After pool DNA sequencing and BLAST analysis, only one novel coding SNP was determined (NC_010454.3: g.341T > C), which resulted in a synonymous mutation. Interestingly, this SNP could be genotyped by the StuI PCRRFLP assay. Hence, for this SNP locus, using the above P1 primer, volume and protocol of the pig TMEM95 gene, PCR amplification was carried out to detect all male piglet individuals in this study. Aliquots of $10 \mu \mathrm{L}$ PCR products with the pig TMEM95 gene were digested with $5 \mathrm{U}$ StuI (MBI, Vilnius, Lithuania) following the supplier's directions for buffer condition. The digested products were detected by electrophoresis in $2.0 \%$ agarose gel stained with ethidium bromide (Wu et al., 2014).

\subsection{Statistical analysis}

Genotypic and allelic frequencies were directly calculated. Polymorphism information content (PIC) was calculated via an online website (http://www.msrcall.com/Gdicall.aspx) (Wu et al., 2014; Jia et al., 2015). The $\chi^{2}$ test was carried out to verify the Hardy-Weinberg equilibrium (HWE). Distribution differences for genotypic and allelic frequencies among/between different breeds were analyzed using the $\chi^{2}$ test, which was carried out using SPSS software (version 18.0) (IBM Corporation, New York, USA) (Yang et al., 2016).

Association tests of the polymorphism (A47A) with three reproduction traits (TW, TLC and TSG) were considered at two different growth periods ( 15 days old/40 days old) in LW piglets, and one period (40 days old) in LD piglets. These association analyses were performed by the procedure of analysis of variance (ANOVA) of the software SPSS (Version 18.0) if data agreed with the characteristic of normality and homogeneity of variances. If data did not agree, a nonparametric test (Kruskal-Wallis) was conducted using software SPSS (18.0). The ANOVA applied the general linear model (GLM) and the reduced linear model was as follows: $Y_{i j k}=\mu+\alpha_{i}+\beta_{j}+\varepsilon_{i j k}$, where $Y_{i j k}=$ the observation of the reproduction trait (e.g., testis weight) evaluated on the $i$ th level of the fixed factor age $\left(\alpha_{i}\right)$, the $j$ th level of the fixed factor genotype $\left(\beta_{j}\right)$, where $\mu=$ the overall mean for each trait and $\varepsilon_{i j k}$ is the random error for the $i j k$ th individual (Henderson et al., 1986; Zhao et al., 2004). Moreover, additive effects were calculated as the mean of the difference between homozygotes, using the least squares means (Falconer et al., 1996). Dominance effects were calculated as the deviation of heterozygotes from the mean of the homozygotes (Short et al., 1997). Allele substitution effects were estimated by using linear regression techniques, regressing phenotypes on the number of copies of the mutant alleles $(0,1$, and/or 2) of this locus (Rothschild et al., 1996). Notably, multiple tests were not corrected at $p=0.05$ or $p=0.01$.

\section{Results}

After the pool sequencing and bioinformatics analysis, the only one novel coding SNP within the pig TMEM95 gene was detected (Fig. 1), namely NC_010454.3: g.341T > C, which was different from other species, e.g., human and bovine. This SNP was found in exon 1, and resulted in synonymous mutation (GCT (47Ala) > GCC (47Ala)).

Interestingly, the novel SNP (A47A) could be genotyped by the $S t u$ I PCR-RFLP assay. In the StuI analysis, genotype TT showed four bands $(872,313,99$, and $86 \mathrm{bp})$, genotype CC demonstrated five bands (779, 313, 99, 93, and $86 \mathrm{bp})$, and genotype TC showed six bands $(872,779,313,99,93$, and $86 \mathrm{bp}$ ) (Fig. 2). Three fragments (99, 93, and $86 \mathrm{bp}$ ) were ignored because they were too close to each other to be able to distinguish between them in the gel, so three longer fragments $(872,779$, and $313 \mathrm{bp})$ were used to identify different genotypes.

As could be seen in Table 2, the genotypic and allelic frequencies of the A47A SNP in the LD and LW breeds were evaluated. The minor allelic frequencies (MAFs) were 


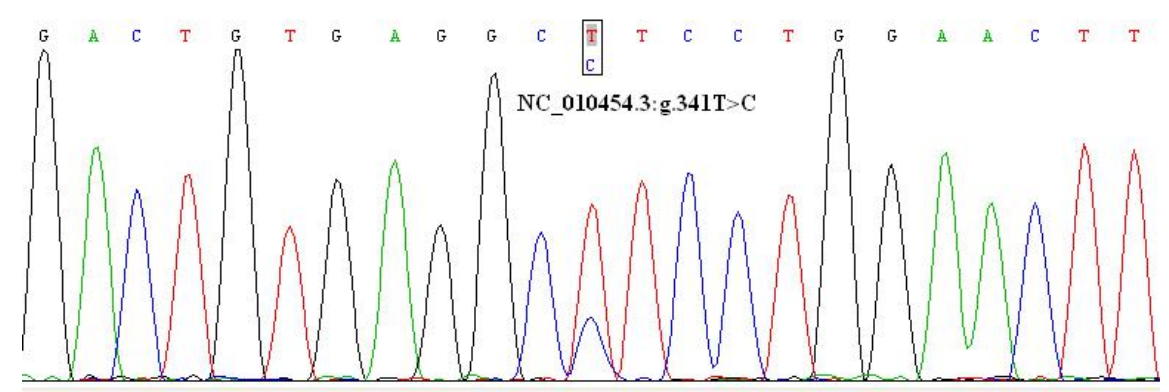

Figure 1. Sequence chromas of the anonymous mutation (NC_010454.3:g.341T > C) in the pig TMEM95 gene.
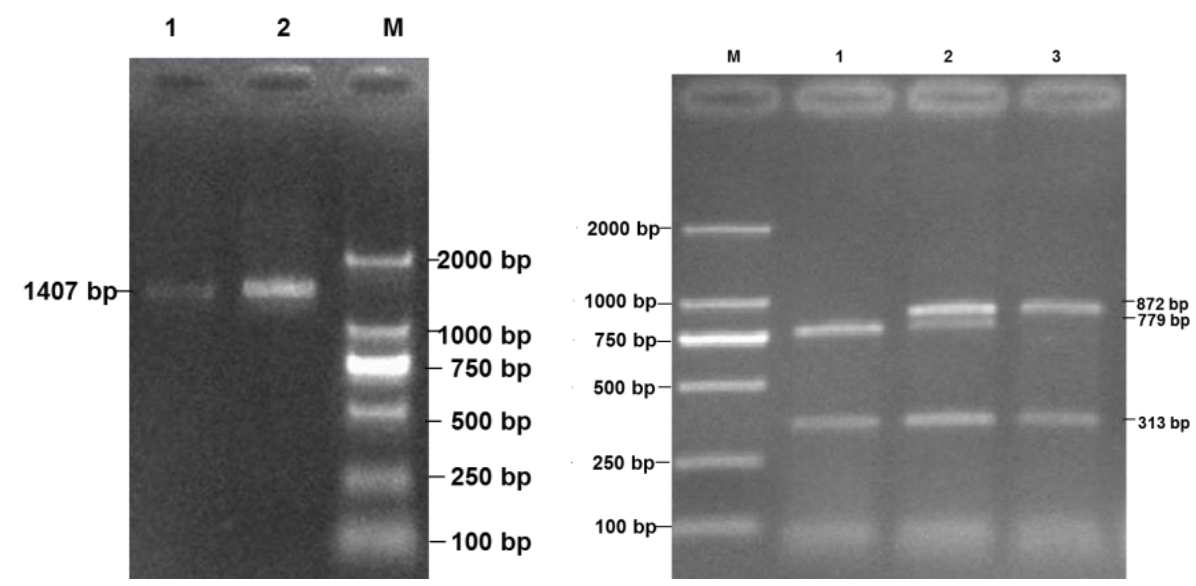

Figure 2. Electrophoresis pattern of the StuI locus within the pig TMEM95 gene.

0.259 (LD) and 0.480 (LW), respectively. The effective allele numbers $(\mathrm{Ne})$ were 1.623 (LD) and 1.997 (LW), respectively. The PIC values of this SNP were 0.310 and 0.375 for the LD and LW breeds, respectively. The LW population was at the Hardy-Weinberg equilibrium (HWE) $(p>0.05)$, whereas the LD was not $(p<0.05)$.

In the two breeds, the associations between this SNP and the pig testis measurement traits were investigated (Table 3). No significant relationship was observed between this novel synonymous SNP and testis measurement traits at 40 days of age in LD pigs. However, a significant relationship was observed between this SNP locus and testis weight at 40 days of age in LW pigs ( $p=0.047)$. The heterozygote individuals showed lower testis weight than those with other genotypes. Moreover, three significant relationships were observed between this SNP locus and testis measurement traits at 15 days of age in LW pigs $(p<0.05)$. Consistently, at the 15 -day-old stage, individuals with genotypes TT and TC showed superior testis measurement traits than those of genotype CC in LW breeds. Moreover, the results based on the additive effect, dominant effect, and allele substitution $(\alpha)$ effects are also shown in Table 4 . There were no significant additive effects, dominant effects, and allele substitution $(\alpha)$ effects between the A47A polymorphism and testis measurement traits in LD breed. However, several significant additive, dominant, and allele substitution $(\alpha)$ effects of this SNP and traits were also revealed $(p<0.05)$.

\section{Discussion}

Previous studies have reported that TMEM95 has a significant association with acrosomal reaction, and it influences sperm fertilizing an egg cell. Therefore, TMEM95 plays an important role in fertility and it is activated and induced during the process of fertilization. To date, no report has described the significant relationships between polymorphisms in the TMEM95 gene and testis measurement traits in pigs. Therefore, it was crucial and necessary to evaluate the associations between the novel SNP of the pig TMEM95 gene and testis measurement traits.

In this study, only one novel coding SNP in the pig TMEM95 gene was firstly reported. For this locus, LD male population was not at Hardy-Weinberg disequilibrium ( $p<$ 0.05 ), implying that the rapid, powerful and effective selection strategies might change the allelic balance of this locus. Statistically, the observed homozygote CC was significantly higher than its expectation. For the LW population, it was at Hardy-Weinberg disequilibrium (HWE) $(p>0.05)$, imply- 
Table 2. Genotypic and allelic frequencies and population indexes for the A47A SNP of the pig TMEM95 gene.

\begin{tabular}{lrrrrrrrrrrr}
\hline Breeds & Sizes & \multicolumn{3}{c}{ Genotypic frequencies } & \multicolumn{2}{c}{ Allelic frequencies } & \multicolumn{2}{c}{ HWE $^{\mathrm{a}}$} & \multicolumn{3}{c}{ Population parameters } \\
\hline & $\mathrm{N}$ & $\mathrm{TT}$ & $\mathrm{TC}$ & $\mathrm{CC}$ & $\mathrm{T}$ & $\mathrm{C}$ & $p$ values & $\mathrm{Ho}^{\mathrm{b}}$ & $\mathrm{He}^{\mathrm{c}}$ & $\mathrm{Ne}^{\mathrm{d}}$ & PIC $^{\mathrm{e}}$ \\
\hline LD & 99 & 0.643 & 0.196 & 0.161 & 0.741 & 0.259 & $p<0.05$ & 0.616 & 0.384 & 1.623 & 0.310 \\
LW & 190 & 0.265 & 0.510 & 0.225 & 0.520 & 0.480 & $p>0.05$ & 0.500 & 0.499 & 1.997 & 0.375 \\
\hline
\end{tabular}

${ }^{a}$ HWE, Hardy-Weinberg equilibrium; ${ }^{b} \mathrm{Ho}$, homozygosity; ${ }^{\mathrm{c}} \mathrm{He}$, heterozygosity; ${ }^{\mathrm{d}} \mathrm{Ne}$, effective allele numbers; ${ }^{\mathrm{e}} \mathrm{PIC}$, polymorphism information content.

Table 3. Relationship between the SNP-StuI of the TMEM95 gene and reproduction traits in pig (least squares means, LSM ${ }^{\mathrm{a}} \pm$ standard error, SE) $(p<0.05)$.

\begin{tabular}{llrrr}
\hline Breeds & Genotype & \multicolumn{3}{c}{ Reproduction traits (LSM $\pm \mathrm{SE})$} \\
\cline { 3 - 5 } & & $\begin{array}{r}\text { Testis long circumference } \\
\text { (TLC) }(\mathrm{cm})\end{array}$ & $\begin{array}{r}\text { Testis short girth } \\
(\mathrm{TSG})(\mathrm{cm})\end{array}$ & $\begin{array}{r}\text { Testis weight } \\
(\mathrm{g})\end{array}$ \\
\hline LD & TT & $6.98 \pm 0.09$ & $5.36 \pm 0.06$ & $6.46 \pm 0.24$ \\
40 days & TC & $7.09 \pm 0.17$ & $5.55 \pm 0.16$ & $7.38 \pm 0.66$ \\
& CC & $6.92 \pm 0.24$ & $5.50 \pm 0.25$ & $6.55 \pm 0.54$ \\
& $p$ values & $p=0.794$ & $p=0.450$ & $p=0.258$ \\
\hline LW & TT & $7.54 \pm 0.14$ & $5.89 \pm 05.89$ & $7.68 \pm 0.41^{\mathrm{a}}$ \\
40 days & TC & $7.33 \pm 0.14$ & $5.79 \pm 0.10$ & $6.71 \pm 0.28^{\mathrm{b}}$ \\
& CC & $7.77 \pm 0.26$ & $5.97 \pm 0.18$ & $7.88 \pm 0.54^{\mathrm{a}}$ \\
& $p$ values & $p=0.269$ & $p=0.649$ & $p=0.047$ \\
\hline LW & TT & $5.39 \pm 0.22^{\mathrm{a}}$ & $4.51 \pm 0.16^{\mathrm{a}}$ & $3.39 \pm 0.36^{\mathrm{a}}$ \\
40 days & TC & $5.39 \pm 0.17^{\mathrm{a}}$ & $4.42 \pm 0.14^{\mathrm{a}}$ & $3.15 \pm 0.27^{\mathrm{a}}$ \\
& CC & $4.77 \pm 0.21^{\mathrm{b}}$ & $3.94 \pm 0.14^{\mathrm{b}}$ & $2.40 \pm 0.22^{\mathrm{b}}$ \\
& $p$ values & $p=0.047$ & $p=0.021$ & $p=0.050$ \\
\hline
\end{tabular}

The values with different letters $\left({ }^{\mathrm{a}}\right.$ and $\left.{ }^{\mathrm{b}}\right)$ within the same column differ significantly at $p<0.05$.

ing that this population was suitable for evaluating the relationship between this SNP and reproduction.

Differences in the distributions of genotypic frequencies for the A47A SNP, based on the $\chi^{2}$ test $\left(\chi^{2}=42.037, \mathrm{df}=2\right.$, $p<0.001$ ), suggesting that there were significantly difference between LW and LD populations. Furthermore, allelic distributions showed significant differences in two breeds, based on the $\chi^{2}$ test $\left(\chi^{2}=26.512, \mathrm{df}=1, p<0.001\right)$. Since the tested breeds represented different reproduction types (such as the LD breed with reproductive barriers, while the LW breed had strong reproduction performance), the genotypic and allelic distributions were demonstrated to have a significant association with reproduction performance. For instance, when compared with the LD breed, the LW breed possessed higher frequencies of the "C" allele, suggesting that this allele was possibly associated with the stronger reproduction traits. Therefore, the pig TMEM95-A47A mutation was assumed to have probable effects on reproduction traits.

Although the novel A47A mutation in the pig TMEM95 gene was a synonymous mutation, it may impart an effect on fitness, splice regulation, and miRNA binding (Parmley et al., 2007). Several computational analyses have also indicated that synonymous mutations impact mRNA stability (Chamary et al., 2005; Quax et al., 2015; Lorenz et al., 2011). Synonymous mutations affected protein folding and function (Parmley et al., 2007; Gartner et al., 2013). Therefore, the relationships between the SNP locus (A47A) and testis measurement traits in piglet were carried out.

Based on the association analysis, the SNP-StuI locus was found to be significantly associated with the testis size in LW pigs $(p<0.05)$. Moreover, genotype $\mathrm{CC}$ individuals was consistently inferior compared to the other genotypes' individuals in LW testis weight and size, suggesting that the allele $\mathrm{T}$ of the pig TMEM95 gene had positive effects on testis measurement traits in this breed. Ghorbankhani (2014) showed that testicular circumference influenced the reproduction of Sanjabi growing ram lambs, independent of nutritional status (Ghorbankhani et al., 2015). In some livestock, testicular volume could reflect spermatogenesis (Gouletsou et al., 2008). Therefore, the identification of individual variation is essential to select and sort the animals for high sperm production potential. There have been some studies on bulls and rams that have shown that testicular morphometry can 
Table 4. Additive, dominance, and allele substitution $(\alpha)$ effects of the A47A mutation in pig TMEM95.

\begin{tabular}{lllrrrrrr}
\hline \multirow{2}{*}{ Breeds } & Age & Effect & \multicolumn{7}{c}{ Types } \\
\cline { 3 - 8 } & & & TLC $(\mathrm{cm})$ & $p$ values & TSG $(\mathrm{cm})$ & $p$ values & $(\mathrm{TW})(\mathrm{g})$ & $p$ values \\
\hline \multirow{2}{*}{ LD } & \multirow{2}{*}{40 days } & Additive & $0.03 \pm 0.11$ & 0.780 & $-0.07 \pm 0.09$ & 0.439 & $-0.04 \pm 0.30$ & 0.885 \\
& & Dominance & $0.14 \pm 0.21$ & 0.501 & $0.12 \pm 0.17$ & 0.481 & $0.88 \pm 0.58$ & 0.132 \\
& $\alpha( \pm$ SE) & $0.01 \pm 0.10$ & 0.943 & $-0.09 \pm 0.08$ & 0.293 & $-0.19 \pm 0.29$ & 0.516 \\
\hline \multirow{2}{*}{ LW } & \multirow{2}{*}{15 days } & Additive & $0.31 \pm 0.16$ & 0.057 & $0.28 \pm 0.12$ & 0.018 & $0.50 \pm 0.22$ & 0.030 \\
& & Dominance & $0.31 \pm 0.24$ & 0.202 & $0.19 \pm 0.17$ & 0.284 & $0.26 \pm 0.33$ & 0.439 \\
& $\alpha( \pm$ SE) & $0.34 \pm 0.16$ & 0.034 & $0.31 \pm 0.11$ & 0.010 & $0.53 \pm 0.22$ & 0.020 \\
\cline { 3 - 8 } & \multirow{2}{*}{40 days } & Additive & $-0.05 \pm 0.16$ & 0.743 & $-0.05 \pm 0.11$ & 0.675 & $-0.09 \pm 0.34$ & 0.784 \\
& Dominance & $-0.37 \pm 0.20$ & 0.076 & $-0.12 \pm 0.15$ & 0.405 & $-1.09 \pm 0.45$ & 0.017 \\
& $\alpha( \pm$ SE) & $0.02 \pm 0.15$ & 0.874 & $-0.02 \pm 0.11$ & 0.840 & $0.13 \pm 0.34$ & 0.700 \\
\hline
\end{tabular}

serve as an indicator of fertility, thus providing high correlations with sperm production (Rege et al., 2000; Devkota et al., 2008).

In the modern pig industry, ultrasonography is generally recognized as the most accurate method for measuring testicular dimensions in England, but it is expensive. However, if we use candidate genes or DNA markers via MAS to improve the testicular size, all costs will be significantly lowered and the accuracy will significantly increase (Schiff et al., 2004). Hence, according to the close relationship between testis measurement traits and reproduction, we suggest that the allele $\mathrm{T}$ of the pig TMEM95 gene had positive effects on reproduction traits.

\section{Conclusions}

We have identified and genotyped a novel A47A mutation within the pig TMEM95 gene, and this SNP was found to significantly affect testis measurement traits, suggesting that TMEM95 could be a candidate gene associated with reproductive traits. These findings could contribute to breeding and genetics programs in the pig industry via MAS.

Data availability. The original data of the paper are available upon request from the corresponding author.

Competing interests. The authors declare that they have no conflict of interest.

Acknowledgements. This work was supported by Fundamental Research Funds for the Central Universities.

Edited by: Steffen Maak

Reviewed by: Faruk Balci and one anonymous referee

\section{References}

Bedford, J. M., Moore, H. D., and Franklin, L. E.: Significance of the equatorial segment of the acrosome of the spermatozoon in eutherian mammals, Exp. Cell Res., 119, 119-126, 1979.

Beerda, B., Wyszynska-Koko, J., Te, Pas. M. F., de, Wit. A. A., and Veerkamp, R. F.: Expression profiles of genes regulating dairy cow fertility: recent findings, ongoing activities and future possibilities, Animal, 2, 1158-1167, 2008.

Bergfelder-Drüing, S., Grosse-Brinkhaus, C., Lind, B., Erbe, M., Schellander, K., Simianer, H., and Tholen, E.: A genomewide association study in large white and landrace pig populations for number piglets born alive, PLoS One, 10, e0117468, https://doi.org/10.1371/journal.pone.0117468, 2015.

Chamary, J. V. and Hurst, L. D.: Biased codon usage near intron-exon junctions: selection on splicing enhancers, splice-site recognition or something else, Trends Genet., 21, 256-259, 2005.

Chen, R., Yu, S., Ren, F., Lv, X. Y., and Pan, C. Y.: Detection of one large insertion/deletion (indel) and two novel SNPs within the SPEF2 gene and their associations with male piglet reproduction traits, Arch. Anim. Breed., 59, 275-283, https://doi.org/10.5194/aab-59-275-2016, 2016.

Devkota, B., Koseki, T., Matsui, M., Sasaki, M., Kaneko, E., Miyamoto, A., Amaya, Montoya. C., and Miyake, Y.: Relationships among age, body weight, scrotal circumference, semen quality and peripheral testosterone and estradiol concentrations in pubertal and postpubertal Holstein bulls, J. Vet. Med. Sci., 70, 119-121, 2008.

Falconer, D. S. and Mackay, T. F. C.: Introduction to Quantitative Genetics, 4th edn, Longman Scientific and Technical, New York, USA, 1996.

Fischer, D., Laiho, A., Gyenesei, A., and Sironen, A.: Identification of reproduction-related gene polymorphisms using whole transcriptome sequencing in the large white pig population, G3Genes Genom. Genet., 5, 1351-1360, 2015.

Fontanesi, L., Bertolini, F., Dall'Olio, S., Buttazzoni, L., Gallo, M., and Russo, V.: Analysis of association between the MUC4 g. $8227 \mathrm{C}>\mathrm{G}$ polymorphism and production traits in Italian heavy pigs using a selective genotyping approach, Anim. Biotechnol., 23, 147-155, 2012.

Gartner, J. J., Parker, S. C., Prickett, T. D., Dutton-Regester, K., Stitzel, M. L., Lin, J. C., Davis, S., Simhadri, V. L., Jha, S., 
Katagiri, N., Gotea, V., Teer, J. K., Wei, X., Morken, M. A., Bhanot, U. K. NISC Comparative Sequencing Program, Chen, G., Elnitski, L. L., Davies, M. A., Gershenwald, J. E., Carter, H., Karchin, R., Robinson, W., Robinson, S., Rosenberg, S. A., Collins, F. S., Parmigiani, G., Komar, A. A., KimchiSarfaty, C., Hayward, N. K., Margulies, E. H., and Samuels, Y.: Whole-genome sequencing identifies a recurrent functional synonymous mutation in melanoma, P. Natl. Acad. Sci. USA, 110, 13481-13486, 2013.

Ghorbankhani, F., Souri, M., Moeini, M. M., and Mirmahmoudi, R.: Effect of nutritional state on semen characteristics, testicular size and serum testosterone concentration in Sanjabi ram lambs during the natural breeding season, Anim. Reprod. Sci., 153, 22-28, 2015.

Gouletsou, P. G., Galatos, A. D., and Leontides, L. S.: Comparison between ultrasonographic and caliper measurements of testicular volume in the dog, Anim. Reprod. Sci., 108, 1-12, 2008.

Henderson, C.: Estimation of variances in animal model and reduced animal model for single traits and single records, J. Dairy Sci., 69, 1394-1402, 1986.

Jia, W., Wu, X., Li, X., Xia, T., Lei, C., Chen, H., Pan, C., and Lan, X.: Novel genetic variants associated with mRNA expression of signal transducer and activator of transcription 3 (STAT3) gene significantly affected goat growth traits, Small Ruminant Res., 129, 25-36, 2015.

Lan, X., Pan, C., Chen, H., Zhang, C, Lia, J., Zhao, M., Lei, C., Zhang, A., and Zhang, L.: An AluI PCR-RFLP detecting a silent allele at the goat POU1F1 locus and its association with production traits, Small Ruminant Res., 73, 8-12, 2007.

Mack, L. A., Lay Jr., D. C., Eicher, S. D., Johnson, A. K., Richert, B. T., and Pajor, E. A.: Growth and reproductive development of male piglets are more vulnerable to midgestation maternal stress than that of female piglets, J. Anim. Sci., 92, 530 548, 2014

Palermo, G. D., Colombero, L. T., and Rosenwaks, Z.: The human sperm centrosome is responsible for normal syngamy and early embryonic development, Rev. Reprod., 2, 19-27, 1997.

Parmley, J. L. and Hurst, L. D.: Exonic splicing regulatory elements skew synonymous codon usage near intron-exon boundaries in mammals, Mol. Biol. Evol., 24, 1600-1603, 2007.

Pausch, H., Kölle, S., Wurmser, C., Schwarzenbacher, H., Emmerling, R., Jansen, S., Trottmann, M., Fuerst, C., Götz, K. U., and Fries, R.: A nonsense mutation in TMEM95 encoding a nondescript transmembrane protein causes idiopathic male subfertility in cattle, PLoS Genet., 10, e1004044, https://doi.org/10.1371/journal.pgen.1004044, 2014.

Quax, T. E., Claassens, N. J., Söll, D., and van der Oost, J.: Codon bias as a means to fine-tune gene expression, Mol. Cell, 59, 149$161,2015$.

Ramasamy, R., Ridgeway, A., Lipshultz, L. I., and Lamb, D. J.: Integrative DNA methylation and gene expression analysis identifies discoidin domain receptor 1 association with idiopathic nonobstructive azoospermia, Fertil. Steril., 102, 968-973, 2014.
Rege, J. E., Toe1, F., Mukasa-Mugerwa, E., Tembely, S., Anindo, D., Baker, R. L., and Lahlou-Kassi, A.: Reproductive characteristics of ethiopian highland sheep. ii. genetic parameters of semen characteristics and their relationships with testicular measurements in ram lambs, Small Ruminant Res., 37, 173187, 2000.

Ren, F., Yu, S., Chen, R., Lv, X. Y., and Pan, C. Y.: Identification of a novel 12-bp insertion/deletion (indel) of iPS-related Oct4 gene and its association with reproductive traits in male piglets, Anim. Reprod. Sci., 178, 55-60, 2017.

Rothschild, M., Jacobson, C., Vaske, D., Tuggle, C., Wang, L., Short, T., Eckardt, G., Sasaki, S., Vincent, A., and McLaren, D.: The estrogen receptor locus is associated with a major gene influencing litter size in pigs, P. Natl. Acad. Sci. USA, 93, 201-205, 1996.

Schiff, J. D., Li, P. S., and Goldstein, M.: Correlation of ultrasonographic and orchidometer measurements of testis volume in adults, BJU Int., 93, 1015-1017, 2004.

Short, T., Rothschild, M., Southwood, O., McLaren, D., De Vries, A., Van der Steen, H., Eckardt, G., Tuggle, C., Helm, J., and Vaske, D.: Effect of the estrogen receptor locus on reproduction and production traits in four commercial pig lines, J. Anim. Sci., 75, 3138-3142, 1997.

Uimari, P., Sironen, A., and Sevón-Aimonen, M. L.: Wholegenome SNP association analysis of reproduction traits in the Finnish landrace pig breed, Genet. Sel. Evol. 43, 42, https://doi.org/10.1186/1297-9686-43-42, 2011.

Wu, X., Jia, W., Zhang, J., Li, X., Pan, C., Lei, C., Chen, H., Dang, R., and Lan, X.: Determination of the novel genetic variants of goat STAT5A gene and their effects on body measurement traits in two Chinese native breeds, Small Ruminant Res., 121, 232-243, 2014.

Yang, Q., Zhang, S., Liu, L., Cao, X., Lei, C., Qi, X., Lin, F., Qu, W., Qi, X., Liu, J., Wang, R., Chen, H., and Lan, X.: Application of mathematical expectation (ME) strategy on detecting the low frequency mutations: an example for evaluating 14-bp insertion/deletion (indel) within the bovine PRNP gene, Prion, 10, 409-419, 2016.

Zhang, S., Cai, H., Yang, Q., Shi, T., Pan, C., Lei, C., Dang, R., Chen, H., and Lan, X.: Novel alternative splicing transcripts identification and expression analysis of bovine TMEM95 gene, Gene, 575, 531-536, 2016.

Zhang, Y. H., Mei, S. Q., Peng, X. W., Niu, B. Y., Ren, Z. Q., Zuo, B., Xu, D. Q., Lei, M. G., Zheng, R., Jiang, S. W., Deng, C. Y., Xiong, Y. Z., and Li, F. E.: Molecular characterization and SNPs analysis of the porcine deleted in azoospermia like (pDAZL) gene, Anim. Reprod. Sci., 112, 415-422, 2009.

Zhao, Q., Davis, M. E., and Hines, H. C.: Associations of polymorphisms in the Pit-1 gene with growth and carcass traits in Angus beef cattle, J. Anim. Sci., 82, 2229-2233, 2004. 